\title{
Association of a transforming growth factor- $\beta 1$ polymorphism with acute coronary syndrome in a Chinese Han population
}

\author{
Y.N. Yang, B. Zhao, X.M. Li, X. Xie, F. Liu and B.D. Chen \\ Department of Cardiology, \\ First Affiliated Hospital of Xinjiang Medical University, Urumqi, China \\ Corresponding author: Y.N. Yang \\ E-mail: yangyn5126@163.com
}

Genet. Mol. Res. 13 (3): 6160-6167 (2014)

Received May 11, 2013

Accepted September 19, 2013

Published April 3, 2014

DOI http://dx.doi.org/10.4238/2014.April.3.2

\begin{abstract}
Acute coronary syndrome (ACS) is a complex multifactorial and polygenic disorder that is thought to result from the interaction between an individual's genetic makeup and various environmental factors. The aim of this study was to investigate the association of a transforming growth factor- $\beta 1$ (TGF- $\beta 1$ ) polymorphism $(-509 \mathrm{C}>\mathrm{T})$ with ACS in a Chinese Han population. The TGF- $\beta 1$ polymorphism was evaluated in 336 patients with ACS and 396 healthy control subjects by polymerase chain reactionrestriction fragment length polymorphism. The genotype distributions of the control and ACS groups were in Hardy-Weinberg equilibrium $\left(\chi^{2}\right.$ $=3.54$ and $\chi^{2}=1.72$, respectively, $\left.\mathrm{P}>0.05\right)$. The frequencies of the $\mathrm{CC}$, CT, and TT genotypes were 22.61, 53.57, and $20.83 \%$ in the ACS group, respectively, whereas they were $8.33,48.74$, and $42.17 \%$ in controls. There were significant differences between controls and ACS patients in the frequencies of the $\mathrm{CC}$ genotype and the $\mathrm{C}$ allele. These results suggest that the promoter polymorphism $(-509 \mathrm{C}>\mathrm{T})$ in $\mathrm{TGF}-\beta 1$ is associated with ACS in this population. The $\mathrm{CC}$ genotype and the $\mathrm{C}$ allele of TGF- $\beta 1$ might be a specific risk factor of ACS in the Chinese Han population in Xinjiang.
\end{abstract}

Key words: Acute coronary syndrome; Gene polymorphism; Transforming growth factor- $\beta 1$; Han nationality 


\section{INTRODUCTION}

Increasingly improved living standards have resulted in more and more patients with coronary heart diseases (CHD). The occurrence of CHD, which poses health risks to elderly people, is affected not only by common factors such as cholesterol, smoking, gender, and age, but also by genetic factors; internal factors that play a critical role in the occurrence and development of such diseases. Several cytokines also play respective roles in atherosclerosis. For instance, transforming growth factor- $\beta 1$ (TGF- $\beta 1$ ) can affect the formation of atherosclerosis through the inflammatory response. Previous studies have shown that TGF- $\beta 1$ is involved in various biological processes including cell proliferation, angiogenesis formulation, lipid metabolism, fibrosis, and immune regulation (Azhar et al., 2003; Rosenkranz, 2004). Thus, TGF- $\beta 1$ plays a critical role in the occurrence and development of CHD through these functions.

The human TGF- $\beta 1$ gene is located on chromosome $19 \mathrm{q} 13$. With a $2.5-\mathrm{kb}$ mRNA, TGF- $\beta 1$ is composed of seven exons and six introns. There is some evidence that the $\mathrm{C}$ to $\mathrm{T}$ single nucleotide polymorphism (SNP) at the -509 position (-509 SNP, Rs 1800469) is associated with the secretion, aggregation, and activation of TGF- $\beta 1$ (Grainger et al., 1999; Luedecking et al., 2000; Silverman et al., 2004). TGF- $\beta 1$ can affect the generation and development of acute coronary syndrome (ACS) through its anti-inflammatory, lipid metabolism, and extracellular matrix effects, as well as through other means. In this study, the association between the TGF$\beta 1-509 \mathrm{C} / \mathrm{T}$ polymorphism and ACS was investigated in a Chinese Han population.

\section{MATERIAL AND METHODS}

\section{Clinical data}

The ACS group comprised 336 patients who were hospitalized in the heart center of the First Teaching Hospital of Xinjiang Medical University between January 2006 and October 2010, and included 201 male patients and 135 female patients with an average age of 56.03 \pm 8.96 years. Diagnoses of patients were in accordance with criteria for ischemic heart disease of the World Health Organization (WHO). Among the patients, 141 suffered from accurate myocardial infarction, and the remaining 195 suffered from unstable angina. All patients' artery stenosis was more than $50 \%$ or even occlusive as confirmed by coronary angiography. The control group was composed of 396 healthy subjects with negative coronary angiography results and no history or family history of cardiovascular diseases, including 231 males and 165 females (average age, $55.05 \pm 9.01$ years). No abnormalities were found in control individuals after detailed inquiry about their medical histories, physical examinations, chest $\mathrm{X}$-rays, standard 12-lead electrocardiograms, hepatobiliary B ultrasounds, and hematuria stool and blood biochemical tests. Members of both groups were of Chinese Han ethnicity, and the age and gender proportions were equal in the two groups. All individuals signed informed consent forms before they were included in the study.

\section{Diagnostic criteria for hypertension and diabetes}

The diagnosis of hypertension was conducted in accordance with the following diag- 
nostic criteria of the Chinese Guideline for Prevention and Treatment of Hypertension (2005 edition): average systolic blood pressure measured on three different days $\geq 140 \mathrm{mmHg}$ ( 1 $\mathrm{mmHg}=0.133 \mathrm{kPa}$ ) and $/$ or average diastolic blood pressure $\geq 90 \mathrm{mmHg}$, and/or patients diagnosed with high blood pressure who were still under treatment. The diagnosis of diabetes was conducted according to the following criteria launched by the WHO in 1999: patients with 12-h fasting blood glucose levels $\geq 7.0 \mathrm{mM}$ or patients with 12-h blood glucose levels $<7$ $\mathrm{mM}$ but who were diagnosed with diabetes and were injected with or were orally administered insulin within 1 month of the study.

\section{Definitions of smokers and alcohol drinkers}

People who smoked at least one cigarette every day on average for more than 1 year were designated as "smokers", and people who drank at least $100 \mathrm{~mL}$ white spirit (containing $50 \%$ alcohol or more) for more than 1 year were designated as "alcohol drinkers". In addition, people who had stopped smoking or drinking alcohol for no more than 1 year were also included in the smoker or alcohol drinker groups.

\section{Collection of clinical data}

The stature and body mass index [BMI; body mass $/$ stature $\left.^{2}\left(\mathrm{~kg} / \mathrm{m}^{2}\right)\right]$ was measured for each subject, whereas information related to medical history, lifestyle, and habits were obtained through questionnaires.

\section{Blood biochemistry index}

Blood was collected from the subjects after fasting for at least $12 \mathrm{~h}$. Total cholesterol, triglycerides, high-density lipoprotein cholesterol (HDL-C), low-density lipoprotein cholesterol (LDL-C), and blood sugar levels of these subjects were tested in the testing center of the First Teaching Hospital of Xinjiang Medical University.

\section{DNA extraction and polymerase chain reaction (PCR) amplification}

DNA was extracted from the leukocytes of peripheral venous blood using the Whole BloodGenome DNA Isolation Kit (BioTeke Corporation, Beijing) according to manufacturer instructions. The primer was designed with the Primer Premier 5 software and was synthesized by the Shanghai Biological Engineering Co., Ltd. (Table 1). PCR amplification required $94^{\circ} \mathrm{C}$ predenaturation for $3 \mathrm{~min}, 96^{\circ} \mathrm{C}$ denaturation for $30 \mathrm{~s}, 55^{\circ} \mathrm{C}$ annealing for $30 \mathrm{~s}$, and a $72^{\circ} \mathrm{C}$ extension for $45 \mathrm{~s}$, for 25 cycles. The target genes, primer sequences, annealing temperatures, and product lengths for the amplification are listed in Table 1.

\section{Digestion and typing of Eco81I}

A 30- $\mu \mathrm{L}$ total reaction system comprising $10 \mu \mathrm{L}$ PCR product, $2 \mu \mathrm{L} 10 \mathrm{X}$ buffer solution, $2 \mathrm{U}$ Eco81I restriction enzyme (produced by Fermentas), and $18 \mu \mathrm{L}$ triple-distilled water 
was placed in a water bath at $37^{\circ} \mathrm{C}$ for $16 \mathrm{~h}$ on $3 \%$ agarose gel (brominated ethidium-stained), then underwent $80 \mathrm{~V}$ electrophoresis for $25 \mathrm{~min}$, and was observed and photographed under ultraviolet light. PCR products and the digestion product were compared with a standard DNA fragment length to identify genotypes.

Table 1. Primer sequence, annealing temperature and fragment length.
\begin{tabular}{llccc} 
& \\
\hline$-509 \mathrm{C} / \mathrm{T}$ & Primer sequence $\left(5^{\prime}-3^{\prime}\right)$ & Annealing temperature $\left({ }^{\circ} \mathrm{C}\right)$ & Cycle number & Fragment length (bp) \\
& $\begin{array}{l}\text { GGAGGTGCTCAGTAAAGGA } \\
\text { GGCTGGGAAACAAGGTAG }\end{array}$ & 56 & 35 & 150 \\
\hline
\end{tabular}

\section{Statistical methods}

The data were processed with the SPSS18.0 software package. The $\chi^{2}$ test was used to assess the control group's representation of the general population based on deviations from Hardy-Weinberg equilibrium and to determine frequency differences between the genotypes and alleles of the groups. Continuous variables were compared with two-way variance analysis. $\mathrm{P}<0.05$ represented statistically significant differences. In addition, logistic regression analysis was used to evaluate the relationships between different genotypes with ACS and to eliminate confounding factors. The degree of association was reported as the odds ratio (OR) with $95 \%$ confidence interval $(\mathrm{CI})$.

\section{RESULTS}

\section{Hardy-Weinberg equilibrium test}

The genotype distributions of the TGF- $\beta 1$ promoter -509 locus of the control and ACS groups were in line with Hardy-Weinberg equilibrium $\left(\chi^{2}=3.53831, \mathrm{P}=0.059967\right.$ and $\chi^{2}=$ $1.721583, \mathrm{P}=0.189489$, respectively), which indicated accurate population representation of the samples.

\section{Comparison of general clinical characteristics between ACS and control groups}

Comparison of clinical characteristics between the ACS and control groups showed that smoking, blood pressure, triglycerides, and cholesterol levels of the ACS group were all significantly lower than those of the control group $(\mathrm{P}<0.05)$ (Table 2$)$.

\section{Gene polymorphism analysis of TGF- $\beta 1$-509C/T (Figure 1)}

The fragment length of the specific product was $150 \mathrm{bp}$ after PCR amplification. The $\mathrm{C}$ allele was cut into two fragments of 62 and 88 bp after Eco81I enzyme digestion, while the $\mathrm{T}$ allele non-restriction locus remained intact as a 150-bp fragment. Therefore, the CC genotype was composed of 62 and 88 bp bands, the CT genotype was composed of 150,62 , and 88 bp bands, and the TT genotype was a 150-bp fragment. 


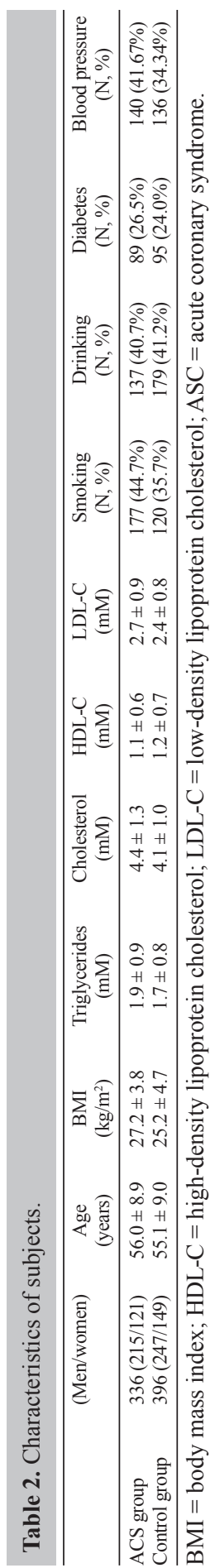




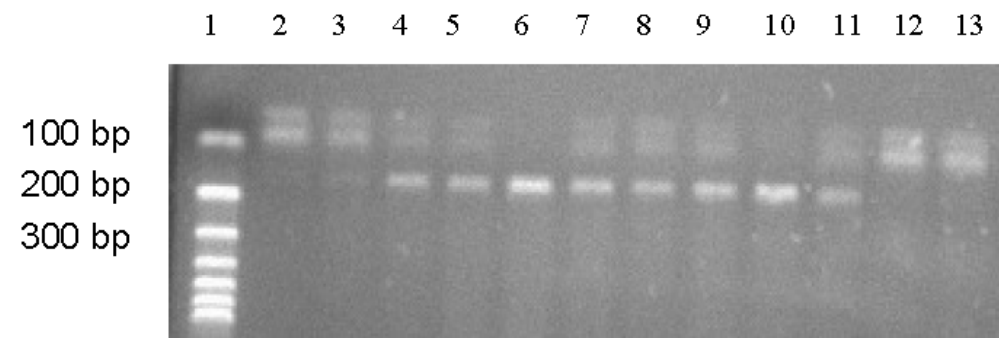

Figure 1. Genotype identification by RFLP. Lane $1=$ DNA marker; lanes 2, 3, 12, and $13=\mathrm{CC}$ genotype; lanes 6 and $10=$ TT genotype; lanes 4, 5, 7, 8, 9, and $11=\mathrm{CT}$ genotype.

\section{Distribution of gene and allele frequencies of ACS and control groups}

Both the ACS group and the control group were mainly composed of the CT genotype, and the $\mathrm{T}$ allele was found in the highest frequency in both groups. However, the distribution of the $\mathrm{CC}$ genotype frequency differed significantly between the two groups $\left(\chi^{2}=25.67, \mathrm{P}<0.01\right)$. The distribution of $\mathrm{C}$ alleles in the two groups also differed significantly $\left(\chi^{2}=38.27, \mathrm{P}<0.01\right)$ (Table 3$)$.

Table 3. Distribution of genotype and allele frequencies of acute coronary syndrome (ACS) and control groups.

\begin{tabular}{|c|c|c|c|c|c|c|}
\hline \multirow[t]{2}{*}{ Group } & \multirow[t]{2}{*}{$\mathrm{N}$} & \multicolumn{3}{|c|}{ Genotype (N, \%) } & \multicolumn{2}{|c|}{ Allelic gene $(\mathrm{N}, \%)$} \\
\hline & & $\mathrm{CC}$ & $\mathrm{CT}$ & $\mathrm{TT}$ & $\mathrm{C}$ & $\mathrm{T}$ \\
\hline ACS & 336 & $76(22.61 \%)$ & $180(53.57 \%)$ & $80(20.83 \%)$ & $332(49.40 \%)$ & $340(50.60 \%)$ \\
\hline Control & 396 & $36(8.33 \%)$ & $193(48.74 \%)$ & $167(42.17 \%)$ & $265(33.46 \%)$ & $527(66.54 \%)$ \\
\hline
\end{tabular}

Compared with the control group, CC genotype: $\chi^{2}=25.67, \mathrm{P}<0.01 ; \mathrm{C}$ allelic gene: $\chi^{2}=38.27, \mathrm{P}<0.01$.

\section{Logistic regression analysis of the multi-factorial relationship between the TGF- $\beta 1$ $-509 \mathrm{C} / \mathrm{T}$ polymorphism and ACS}

Multi-factorial and non-conditional logistic regression analysis was conducted considering ACS as the dependent variable and smoking and drinking history, hypertension, diabetes, cholesterol, triglyceride, age, and the TGF- $\beta 1-509 \mathrm{C} / \mathrm{T}$ polymorphism as independent variables. Non-distinctive variables were gradually picked up or ruled out (progressive and retreating method) on the condition of $\alpha=0.05$. The variables ultimately included in the main effect model were smoking, hypertension, the TGF- $\beta 1$-509CC genotype, cholesterol, triglycerides, LDL-C, and high blood pressure (Table 4).

Table 4. Logistic regression analysis of the multi-factorial relationship between the TGF- $\beta 1$ polymorphism$509 \mathrm{C} / \mathrm{T}$ and acute coronary syndrome.

\begin{tabular}{lllcccc}
\hline & $\mathrm{B}$ & $\mathrm{SE}$ & Wald $\chi^{2}$ & $\mathrm{P}$ & OR & 95\%CI \\
\hline Triglycerides & 0.232 & 0.095 & 6.038 & 0.014 & 1.262 & $1.048-1.518$ \\
Cholesterol & 0.21 & 0.76 & 7.591 & 0.006 & 1.233 & $1.062-1.436$ \\
HDL-C & 0.217 & 0.128 & 2.868 & 0.09 & 0.805 & $0.627-1.035$ \\
LDL-C & 0.374 & 0.095 & 15.559 & $<0.01$ & 1.453 & $1.207-1.750$ \\
Smoking & 0.94 & 0.155 & 36.99 & $<0.01$ & 2.56 & $1.890-3.466$ \\
Diabetes & 0.132 & 0.171 & 0.602 & 0.438 & 1.142 & $0.817-1.595$ \\
Blood pressure & 0.312 & 0.153 & 4.14 & 0.42 & 1.366 & $1.012-1.843$ \\
CC genotype & 1.073 & 0.218 & 24.192 & $<0.01$ & 2.923 & $1.906-4.482$ \\
\hline
\end{tabular}

HDL-C = high-density lipoprotein cholesterol; LDL-C = low-density lipoprotein cholesterol. 


\section{DISCUSSION}

As a member of the TGF superfamily, TGF- $\beta 1$ is mostly found in vascular smooth muscle cells, endothelial cells, hematopoietic cells, and macrophages (Annes et al., 2003). TGF- $\beta 1$ affects the occurrence and development of ACS by influencing the inflammatory response, lipid metabolism, and the extracellular matrix of cells, as well as by other means. Accordingly, the genetic polymorphism of the -509 site of TGF- $\beta 1$ affects the occurrence and development of ACS by affecting the secretion, aggregation, and activation of TGF- $\beta 1$ (Grainger et al., 1999; Luedecking et al., 2000; Silverman et al., 2004). Several studies have shown that this TGF- $\beta 1$ polymorphism is associated with coronary heart diseases (Wang et al., 1998; Yokota et al., 2000; Koch et al., 2006; Sie et al., 2006; Crobu et al., 2008; Chen et al., 2012).

A large number of studies have shown a high diversity and heterogeneity of polymorphisms of the TGF- $\beta 1$ gene across different races. Most of the studies related to TGF- $\beta 1$ polymorphisms in Chinese populations have focused on hypertension, and studies examining the relationship between ACS and TGF- $\beta 1$ genetic polymorphisms are relatively scarce.

The results of this study showed that the TGF- $\beta 1$ promoter $-509 \mathrm{C} / \mathrm{T}$ polymorphism is closely associated with the occurrence of ACS in the Chinese Han population of Xinjiang; however, the $\mathrm{C}$ allele plays a different role in this population and its frequency differs from those reported in other ethnic groups. Although several studies have investigated the association between the TGF- $\beta 1$ promoter $-509 \mathrm{C} / \mathrm{T}$ polymorphism and ACS, the results are generally inconsistent. In an Italian study, Crobu et al. (2008) showed that the $\mathrm{C}$ allele of promoter $-509 \mathrm{C} / \mathrm{T}$ is a protective factor for acute myocardial infarction, which was similarly observed by Koch et al. (2006). However, Sie et al. (2006) showed that the $-509 \mathrm{C} / \mathrm{T}$ mutation had no influence on acute myocardial infarction. Given the fact that most previous studies of $-509 \mathrm{C} / \mathrm{T}$ were conducted in Europe, these contrasting results may be related to racial heterogeneity. Furthermore, the influence of the promoter -509C/T SNP has mainly focused on the C allele. The present study showed that the $\mathrm{T}$ allele plays a leading role in the occurrence of acute myocardial infarction in people of Han ethnicity in Xinjiang, whereas the $\mathrm{C}$ allele is closely related to the occurrence of ACS, which differs from previous results showing a protective role of the $\mathrm{C}$ allele. In summary, the $\mathrm{C}$ allele of the TGF- $\beta 1$ promoter $-509 \mathrm{C} / \mathrm{T}$ polymorphism represents a genetic marker in patients with ACS of Han ethnicity in Xinjiang.

\section{REFERENCES}

Annes JP, Munger JS and Rifkin DB (2003). Making sense of latent TGFbeta activation. J. Cell Sci. 116: $217-224$.

Azhar M, Schultz JJ, Grupp I, Dorn GW, et al. (2003). Transforming growth factor beta in cardiovascular development and function. Cytokine Growth Factor Rev. 14: 391-407.

Chen Y, Dawes PT, Packham JC and Mattey DL (2012). Interaction between smoking and functional polymorphism in the TGFB1 gene is associated with ischaemic heart disease and myocardial infarction in patients with rheumatoid arthritis: a cross-sectional study. Arthritis Res. Ther. 14: R81.

Crobu F, Palumbo L, Franco E, Bergerone S, et al. (2008). Role of TGF-beta1 haplotypes in the occurrence of myocardial infarction in young Italian patients. BMC Med. Genet. 9: 13.

Grainger DJ, Heathcote K, Chiano M, Snieder H, et al. (1999). Genetic control of the circulating concentration of transforming growth factor type beta1. Hum. Mol. Genet. 8: 93-97.

Koch W, Hoppmann P, Mueller JC, Schömig A, et al. (2006). Association of transforming growth factor- $\beta 1$ gene polymorphisms with myocardial infarction in patients with angiographically proven coronary heart disease. Arterioscler. Thromb. Vasc. Biol. 26: 1114-1119. 
Luedecking EK, DeKosky ST, Mehdi H, Ganguli M, et al. (2000). Analysis of genetic polymorphisms in the transforming growth factor-betal gene and the risk of Alzheimer's disease. Hum. Genet. 106: 565-569.

Rosenkranz S (2004). TGF-beta1 and angiotensin networking in cardiac remodeling. Cardiovasc. Res. 63: 423-432.

Sie MP, Uitterlinden AG, Bos MJ, Arp PP, et al. (2006). TGF-beta 1 polymorphisms and risk of myocardial infarction and stroke: the Rotterdam study. Stroke 37: 2667-2671.

Silverman ES, Palmer LJ, Subramaniam V, Hallock A, et al. (2004). Transforming growth factor-beta1 promoter polymorphism C-509T is associated with asthma. Am. J. Respir. Crit. Care Med. 169: 214-219.

Wang XL, Sim AS and Wilcken DE (1998). A common polymorphism of the transforming growth factor-beta1 gene and coronary artery disease. Clin. Sci. 95: 745-746.

Yokota M, Ichihara S, Lin TL, Nakashima N, et al. (2000). Association of a T29 $\rightarrow$ C polymorphism of the transforming growth factor-beta1 gene with genetic susceptibility to myocardial infarction in Japanese. Circulation 101: 2783-2787. 